\title{
Providing Performance Evaluation Indicators for Intelligent Transportation Systems (The Case Study of Tehran-Karaj Freeway Located in Iran)
}

\author{
Arshia Taimouri ${ }^{*}$, Korosh Emamisaleh$^{2}$ \\ ${ }^{1}$ Department of Management, University of Ershad Damavand, Tehran, Iran \\ ${ }^{2}$ Department of Industrial Management, Islamic Azad University South Tehran Branch, Tehran, Iran \\ Email: *arshiateimouri@gmail.com
}

How to cite this paper: Taimouri, A. and Emamisaleh, K. (2020) Providing Performance Evaluation Indicators for Intelligent Transportation Systems (The Case Study of Tehran-Karaj Freeway Located in Iran). Journal of Transportation Technologies, 10, 144-153.

https://doi.org/10.4236/jtts.2020.102009

Received: February 2, 2020

Accepted: March 21, 2020

Published: March 24, 2020

Copyright $\odot 2020$ by author(s) and Scientific Research Publishing Inc. This work is licensed under the Creative Commons Attribution International License (CC BY 4.0).

http://creativecommons.org/licenses/by/4.0/

cc) (i) Open Access

\begin{abstract}
Intelligent Transportation Systems (ITS) play a fundamental role in reducing traffic congestion and increasing safety during daily transportation. These systems can also be useful in improving social welfare leading to general satisfaction. Proper performance evaluation can be efficient in improving the performance of these systems, and providing a scientific assessment index system can assist decision-makers in smart communities to plan for the development of ITS. However, the evaluation of these systems requires identifying appropriate indicators of performance evaluation that are consistent with the views of the beneficiaries of these systems. In this paper, performance evaluation indicators of ITS have been identified, and three indicators entitled "environmental and safety", "assistance in reducing traffic congestion" and "attractive public transport" are presented to evaluate the performance of these systems. Moreover, the intelligent transport systems of the Tehran-Karaj Freeway in Iran are studied, and inferential statistical methods are employed to test the research hypotheses. It is worth noticing that in this study, a one-sample T-test method is used for hypotheses assessment and the SPSS software was used to analyze the findings. Also, the results demonstrated that the performance of ITS in the Tehran-Karaj Freeway regarding the indicators, such as "Declaration of route blocking information due to maintenance or reconstruction" and "Declaration of path geometry conditions" has not been acceptable.
\end{abstract}

\section{Keywords}

Performance Evaluation, Intelligent Transportation Systems, Evaluation Indicators 


\section{Introduction}

Due to the rapid growth of urban population and urbanization in recent years, along with the apace development of technology, transportation problems, such as environmental pollution, reducing energy resources, increasing the damages derived from accidents, suburban transportation management, the increment of wasted times and the rapid increase in transportation demand, especially during rush hours have gained a dramatic amount of attention. The development of the transportation facilities requires massive investments and considerable time to run, and these have generated a large number of restrictions in this regard. Thus, overcoming the problems through relying on traditional control methods seems impossible. Also, following the advances in communications technology and electronics, intelligent transportation systems (ITS) have been studied more profoundly since the 1980s [1].

The benefits of ITS concerning both costs and the quality of controlling are unique and remarkable. Intelligent transportation systems are about applying a set of advanced technologies and equipment, such as sensors, processors, and communications technology in transport systems, creating the possibility that the different parts of transportation management automatically interact with each other so that an integrated transportation network is to be managed. This technology develops the performance of traditional transportation by using the electronic exchange of data and information. These systems manage the transport structure to curb the needed time for trips according to the space and capacity of the transport vehicles, population growth, and the increase in travel rates. In this way, road transport capacity is enhanced without increasing the physical road lanes. The use of intelligent transportation systems enables both the government and the private sector to utilize new technologies to improve safety, security, information accuracy, comfort, increase traffic congestion dynamics, and reduce fuel consumption and pollution. Using ITS expands the quality and access to information for both service providers and clients (drivers) and also prepares a condition to employ the equipment and identical services in different environments [2]. In recent years, the use of intelligent transportation systems has been developed, and the majority of countries throughout the world utilize these kinds of systems at different levels of technology. In Iran, these systems are used in the towns and roads between cities. However, a significant point in using ITS is the performance appraisal of these systems that should be accomplished based on appropriate indicators.

Previous research identified various performance indicators for evaluating intelligent transportation systems. [3] decided to develop a set of performance indicators for the practical assessment of transportation systems in a smart city located in China. They divided this set of indicators into the following six categories: transport structure, traffic information service, traffic efficiency, traffic safety, energy, and pollution reduction as well as social inclusion. Finally, having calculated the index, they concluded that their proposed sets of indicators are 
suitable for assessing the performance of transportation systems in smart cities according to big data. Also, [1] suggested a pragmatic framework to evaluate the economic benefits of ITS projects from the societal point of view. They did their study in China and stated that these systems help to curb travel and fuel costs and increase the capacity of roads that consequently, this trend leads to the economic development of a society. In a study conducted by [4], an anomaly detection method was employed to appraise the road traffic data in intelligent transportation systems. This method is based on multi-channel singular spectrum analysis (MSSA) intending to determine the spatio-temporal properties of the transportation network. [5] considered the factor of feasibility in studying an ITS project's lifecycle.

On the one hand, the performance evaluation of these systems with suitable indicators leads to the improvement of technology levels of these systems, and on the other hand, the increment of users' satisfaction is expected, since generally speaking in the management science the performance evaluation is the first step through moving toward improvement and corrective actions. According to the Deming Cycle (PDCA), proper evaluation can cause the improvement of performance and the modification of probable mistakes. Besides, based on the study of [6], considering the comments of customers about the products results in quality improvement. In addition, [7] examined the speed control and intelligent transportation systems by concentrating on the views of drivers. They showed that their perception of these systems is positive, and they believe that deploying these systems will give us an awareness of the traffic situation and also increases driving safety.

Tehran Karaj Freeway is one of the busiest road axes between Tehran and Alborz provinces in Iran. Besides, according to information available on the websites of Iran Road Maintenance \& Transportation Organization ${ }^{1}$ and Road Management Center ${ }^{2}$, there are four intelligent control systems on this freeway. These systems include video surveillance and speed cameras. Hence, in this paper, according to the importance of this central freeway, we aim to provide indicators for performance evaluation of intelligent transport systems on this freeway. So, we endeavour to respond to the following fundamental question:

Which indicators can be used for the performance evaluation of intelligent transport systems on the Tehran-Karaj freeway?

\section{Intelligent Transportation Systems}

ITS have been developed since the beginning of the 1970s [8] and formerly they come from the term Intelligent Vehicle Highway Systems (IVHS) presented by the University of Michigan Transportation Research Institute (1988) to determine the usage of computer, communication, and automation technologies for meliorating the safety and efficiency of traffic [9]. ITS encompass two components named, ATIS (Advanced Traveler Information Systems) and ATMS (Ad${ }^{1}$ http://www.rmto.ir/Pages/Home.aspx.

${ }^{2}$ https://www.141.ir/. 
vanced Traffic Monitoring System). ATIS provides the required information for ITS, and ATMS supplies the surveillance, detection, and response aspects of Intelligent Transportation Systems [10]. By reviewing the literature, it is cogent that there are several definitions of intelligent transportation systems. According to a definition, it can be defined as "the application of computing, information, and communications technologies to the real-time management of vehicles and networks involving the movement of people, goods, and services" [11]. Besides, Intelligent transportation systems is a generic term for the combined use of communication technologies, control, and information processing systems for transportation systems. Generally, the term "intelligent transportation system" is applied to mention "the integration of control, information and communication technologies with transport infrastructure”. When these systems are integrated into the infrastructure of the transportation system as well as vehicles themselves, they alleviate congestion, improve safety, and increase productivity [12]. The application of such systems leads to saving lives, time, money, energy, and environmental benefits. ITS include all modes of transportation and covers the dynamic interaction of all components of the transport system. Being widely applicable in various modes of transport is the main merit of Intelligent Transport Systems. The core task of these systems is to improve decision making (especially on-spot) of transportation networks' controllers and other users and, as a result, to enhance the overall application of the transportation system. This definition involves a wide range of techniques and strategies that can be achieved by employing technology or improvement in a set of transportation technologies [13]. Information is the focal point of ITS that can be in the following forms: fixed data, updated and recent traffic data, and digital map. Most of the ITS tools are based on gathering, processing, combining, and preparing the information. Data collected by ITS can prepare updated information about the current condition of the roads network or the information for planning a trip. Also, this set of data supply better, healthier and more harmonious information for the decision-makers of roads and associated companies, public transport, and commercial service providers plus private travelers in order to use the road network more intelligently [14]. By applying ITS technologies, the transportation systems would be smarter, greener, and more efficient.

ITS is employed in the following scopes: 1-The management and monitoring the traffic, 2-Traffic optimization, 3-Driving autonomously, 4-Identifying the status of driver, 5-Identifying the mechanism of driver behavior and 6-Preventing and analyzing car accidents [12] and its primary goal is to employ appropriate technologies to generate more intelligent users, vehicles and roads [15]. To sum up, due to having some specific characteristics, such as 1-automated computation, 2-flexibility, 3-providing precise, accurate and up-to-date information and 4-owning asynchronous and distributed algorithms for control, coordination and resource management undoubtedly in the near future intelligent transportation systems will attain increasing importance [16]. 


\section{Research Conceptual Model}

Relying on the studies and environmental features of the Tehran - Karaj Freeway and in order to identify indicators for evaluating the performance of intelligent transport systems, three indicators of environmental and safety, Assistance in reducing congestion, and attractive public transport are recommended. It is noteworthy that each of these sub-indices is shown in Table 1 (Figure 1).

Hence, based on the proposed model, the hypotheses of the present study are as follows:

$\mathrm{H}_{1}$ : Environmental and safety indicator and proposed sub-indicators are appropriate indicators to evaluate the performance of Intelligent Transportation Systems in the Tehran-Karaj Freeway.

$\mathrm{H}_{2}$ : Assistance in reducing congestion indicator and proposed sub-indicators

Table 1. Evaluation of intelligent transport systems indicators in Tehran-Karaj freeway derived from (ITS Handbook 2000, 1999).

\begin{tabular}{|c|c|}
\hline Main indicators & Sub-indicators \\
\hline $\begin{array}{c}\text { Environmental } \\
\text { and safety indicator }\end{array}$ & $\begin{array}{l}\text { 1) Declaration of path geometry conditions (such as screws and slope). } \\
\text { 2) Diagnosis and prediction of air pollution. } \\
\text { 3) Forecasting weather conditions. } \\
\text { 4) Warning about exceeding the safe speed. } \\
\text { 5) Providing safe speed selection information along the way. } \\
\text { 6) Coordination with agencies responsible for emergency relief. } \\
\text { 7) Controlling and monitoring suspicious vehicles. }\end{array}$ \\
\hline $\begin{array}{l}\text { Assistance in reducing } \\
\text { congestion indicator }\end{array}$ & $\begin{array}{l}\text { 1) Declaration of route blocking information due to maintenance or } \\
\text { reconstruction. } \\
\text { 2) Alternative route guide. } \\
\text { 3) Inputs and outputs control of the route } \\
\text { 4) Law enforcement through collecting violation evidence }\end{array}$ \\
\hline $\begin{array}{l}\text { Attractive public } \\
\text { transport indicator }\end{array}$ & $\begin{array}{l}\text { 1) Announcing route traffic and suggesting public transportation } \\
\text { alternatives. } \\
\text { 2) Announcing the exact departure time of public transportation } \\
\text { alternatives. }\end{array}$ \\
\hline
\end{tabular}

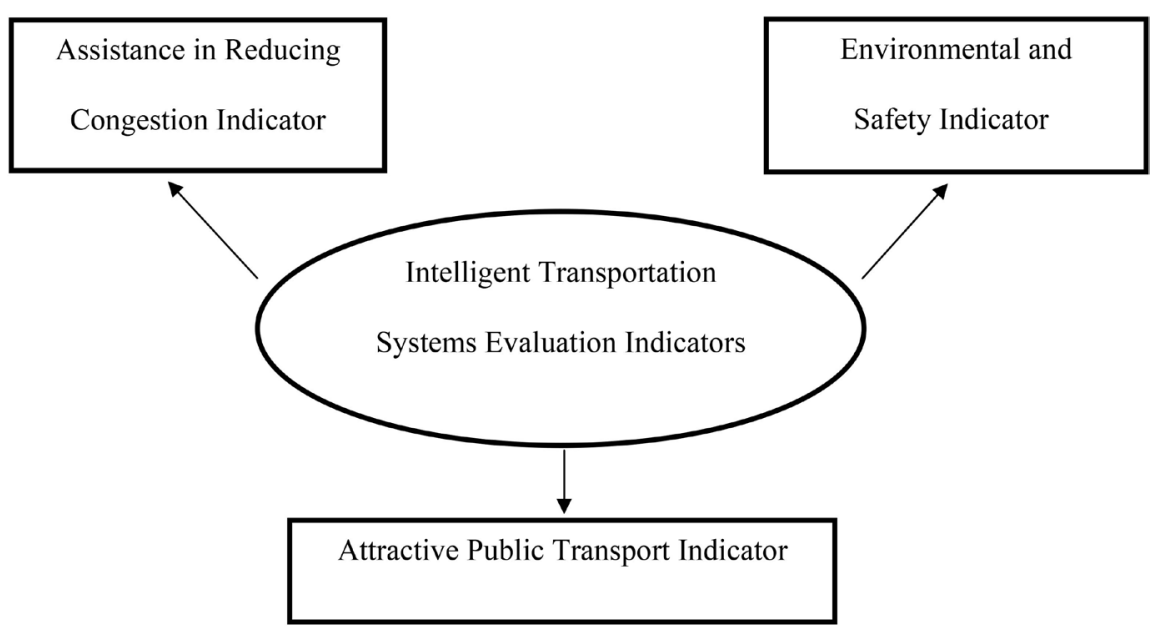

Figure 1. Research conceptual model. 
are appropriate indicators to evaluate the performance of Intelligent Transportation Systems in the Tehran-Karaj Freeway.

$\mathrm{H}_{3}$ : Attractive public transport and proposed sub-indicators are appropriate indicators to evaluate the performance of Intelligent Transportation Systems in the Tehran-Karaj Freeway.

\section{Research Method}

This research is a questionnaire-based study. The questionnaire has been designed according to the conceptual model. Each indicator is measured based on the Five-point Likert scale ranging from 1 to 5 , which 1 indicating "strongly disagree" and 5 "strongly agree". We assessed the validity of the questionnaire throughout content validity. Several experts and professors have confirmed the face validity of the current questionnaire. The reliability is assessed using Cronbach's alpha in a prototype 50 that results are shown in Table 2. Also, the statistical society of this study includes all people who have used their cars in public transport fleet and directly in the Tehran-Karaj freeway in one month. In this case, given the reviews of the current situation and the limitations, 120 of these people are selected for the study. Probability sampling (simple incidental sampling) has been used in this study. There are about 20 females and 80 males in the sample, and the average of ages in this sample is 33 years. Of those, $70 \%$ and $30 \%$ have a college education and high school diploma respectively.

\section{Testing Research Hypotheses and Results}

In this section, we test the research hypotheses. After the test, we should review the behavior of the main variables for normality. Accordingly, by deploying the Kolmogorov-Smirnov test, which its results are shown in Table 3, it was found that three variables have normal behavior. Based on the normality of these variables, to test the research hypotheses, a one-sample T-test is proposed. Besides, since the numbers 4 and 5 represent terms "agree" and "strongly agree" in the questionnaire if number 3 is chosen as the test number and all variables gain a score higher than 3, it means that the majority of the respondents agreed with the index. The results of testing the main hypotheses and sub-indicators are demonstrated in Table 4 and Table 5. In this case, we used Equation (1) to perform the One-Sample T-test and relevant calculations are conducted using the SPSS software.

$$
t=\frac{\bar{x}-\mu}{\frac{s}{\sqrt{n}}}
$$

Equation (1). One-sample T-test

The sample mean $(\bar{x})$ - The population mean $(\mu)$

The sample standard deviation $(s)$-Number of observations $(n)$

According to the findings in Table 4, all the leading indicators as the indicators for assessing the Intelligent Transportation Systems (ITS) are approved (the 
Table 2. The reliability of the research question.

\begin{tabular}{ccc}
\hline Indicator Name & Number of Questions & Cronbach's Alpha \\
\hline Environmental and safety indicator & Seven questions & 0.829 \\
Assistance in reducing congestion indicator & Four questions & 0.719 \\
Attractive public transport indicator & Two questions & 0.757 \\
\hline
\end{tabular}

Table 3. Kolmogorov test results.

\begin{tabular}{cccc}
\hline $\begin{array}{c}\text { Attractive public transport } \\
\text { indicator }\end{array}$ & $\begin{array}{c}\text { Assistance in reducing } \\
\text { congestion indicator }\end{array}$ & $\begin{array}{c}\text { Environmental and } \\
\text { safety indicator }\end{array}$ & Main indexes \\
\hline 1.281 & 1.292 & 1.328 & k-s statistic \\
0.066 & 0.071 & 0.059 & Significant \\
Normal & Normal & Normal & Result \\
\hline
\end{tabular}

Table 4. Test results of the research hypotheses.

\begin{tabular}{|c|c|c|c|c|c|c|}
\hline \multirow{3}{*}{$\begin{array}{l}\text { Environmental and } \\
\text { safety indicator }\end{array}$} & \multirow{3}{*}{$\begin{array}{c}\mathrm{t} \\
9.503\end{array}$} & \multirow{3}{*}{$\begin{array}{c}\text { Degrees of } \\
\text { Freedom } \\
119\end{array}$} & \multirow{3}{*}{$\begin{array}{c}\begin{array}{c}\text { Significant } \\
\text { Level }\end{array} \\
0.000\end{array}$} & \multirow{3}{*}{$\begin{array}{c}\text { Difference } \\
\text { from the mean } \\
0.65000\end{array}$} & \multirow{2}{*}{\multicolumn{2}{|c|}{$\frac{\text { Confidence interval 95\% }}{\text { Upper limit Lower limit }}$}} \\
\hline & & & & & & \\
\hline & & & & & 0.5146 & 0.7854 \\
\hline $\begin{array}{l}\text { Assistance in reducing } \\
\text { congestion indicator }\end{array}$ & 8.708 & 119 & 0.000 & 0.60625 & 0.4684 & 0.7441 \\
\hline $\begin{array}{l}\text { Attractive public } \\
\text { transport indicator }\end{array}$ & 15.147 & 119 & 0.000 & 0.89583 & 0.7787 & 1.0129 \\
\hline
\end{tabular}

Table 5. Test results of the sub-indicators.

\begin{tabular}{|c|c|c|c|c|c|c|}
\hline & \multirow{2}{*}{$\mathrm{T}$} & \multirow{2}{*}{$\begin{array}{l}\text { Degrees of } \\
\text { freedom }\end{array}$} & \multirow{2}{*}{ Significant level } & \multirow{2}{*}{ Mean Difference } & \multicolumn{2}{|c|}{ Confidence interval $95 \%$} \\
\hline & & & & & Upper limit & Lower limit \\
\hline $\begin{array}{l}\text { Declaration of path geometry conditions (such as screws } \\
\text { and slopes) }\end{array}$ & 1.070 & 119 & 0.287 & 0.13333 & -0.1135 & 0.3801 \\
\hline Diagnosis and prediction of air pollution & 8.462 & 119 & 0.000 & 0.78333 & 0.6000 & 0.9666 \\
\hline Forecasting weather conditions & 7.702 & 119 & 0.000 & 0.73333 & 0.5448 & 0.9219 \\
\hline Warning about exceeding the safe speed & 9.132 & 119 & 0.000 & 0.68333 & 0.5352 & 0.8315 \\
\hline Providing safe speed selection information along the way & 7.029 & 119 & 0.000 & 0.72500 & 0.5208 & 0.9292 \\
\hline $\begin{array}{l}\text { Coordination with agencies responsible for emergency } \\
\text { relief }\end{array}$ & 9.867 & 119 & 0.000 & 0.75000 & 0.5995 & 0.9005 \\
\hline Controlling and monitoring suspicious vehicles & 7.029 & 119 & 0.000 & 0.74167 & 0.5327 & 0.9506 \\
\hline $\begin{array}{l}\text { Declaration of route blocking information due to } \\
\text { maintenance or reconstruction }\end{array}$ & 1.969 & 119 & 0.051 & 0.20833 & -0.0011 & 0.4178 \\
\hline Alternative route Guide & 3.455 & 119 & 0.001 & 0.35833 & 0.1530 & 0.5637 \\
\hline Inputs and outputs control of the route & 14.989 & 119 & 0.000 & 1.03333 & 0.8968 & 1.1698 \\
\hline Law enforcement through collecting violation evidence & 8.669 & 119 & 0.000 & 0.82500 & 0.6366 & 1.0134 \\
\hline $\begin{array}{l}\text { Announcing route traffic and suggesting public } \\
\text { transportation alternatives }\end{array}$ & 13.382 & 119 & 0.000 & 0.93333 & 0.7952 & 1.0714 \\
\hline $\begin{array}{l}\text { Announcing the exact departure time of public } \\
\text { transportation alternatives }\end{array}$ & 13.882 & 119 & 0.000 & 0.85833 & 0.7359 & 0.9808 \\
\hline
\end{tabular}


significance level is less than 0.05). Also, according to Table 5, two sub-indicators entitled "Declaration of path geometry conditions (such as screws and slope)" and "Declaration of route blocking information due to maintenance or reconstruction" are rejected and subsequently are removed from the final proposed model. However, other sub-indicators are accepted.

\section{Conclusions}

In this study, we have identified three main indicators, called "Environmental and Safety", "Attractive public transport" and "Assistance in reducing congestion" for appraising the performance of intelligent transportation systems. All the sub-indicators related to the main indicators mentioned above except "Declaration of path geometry conditions (such as screws and slopes)" and "Declaration of route blocking information due to maintenance or reconstruction" have shown their appropriateness for the performance evaluation of Intelligent Transportation Systems meaning that these sub-indicators are reliable, and by improving each one, the performance amelioration of intelligent transportation systems is expected since one of the factors hindering the development of these systems is the lack of accurate evaluation of the current condition of a system [17]. The rejection of the aforementioned two sub-indicators depicting the weakness of Intelligent transportation systems located in the Tehran-Karaj freeway regarding these two sub-indicators, clarifying that the performance is not adequate and more emphasis must be dedicated in order to improve the performance of Intelligent Transportation Systems in this regard (Figure 2).

However, this study has some limitations. Generally, although there are several leading and crowded routes in Iran, due to the lack of sufficient financial resources, this study is exclusively based on one of the leading transportation

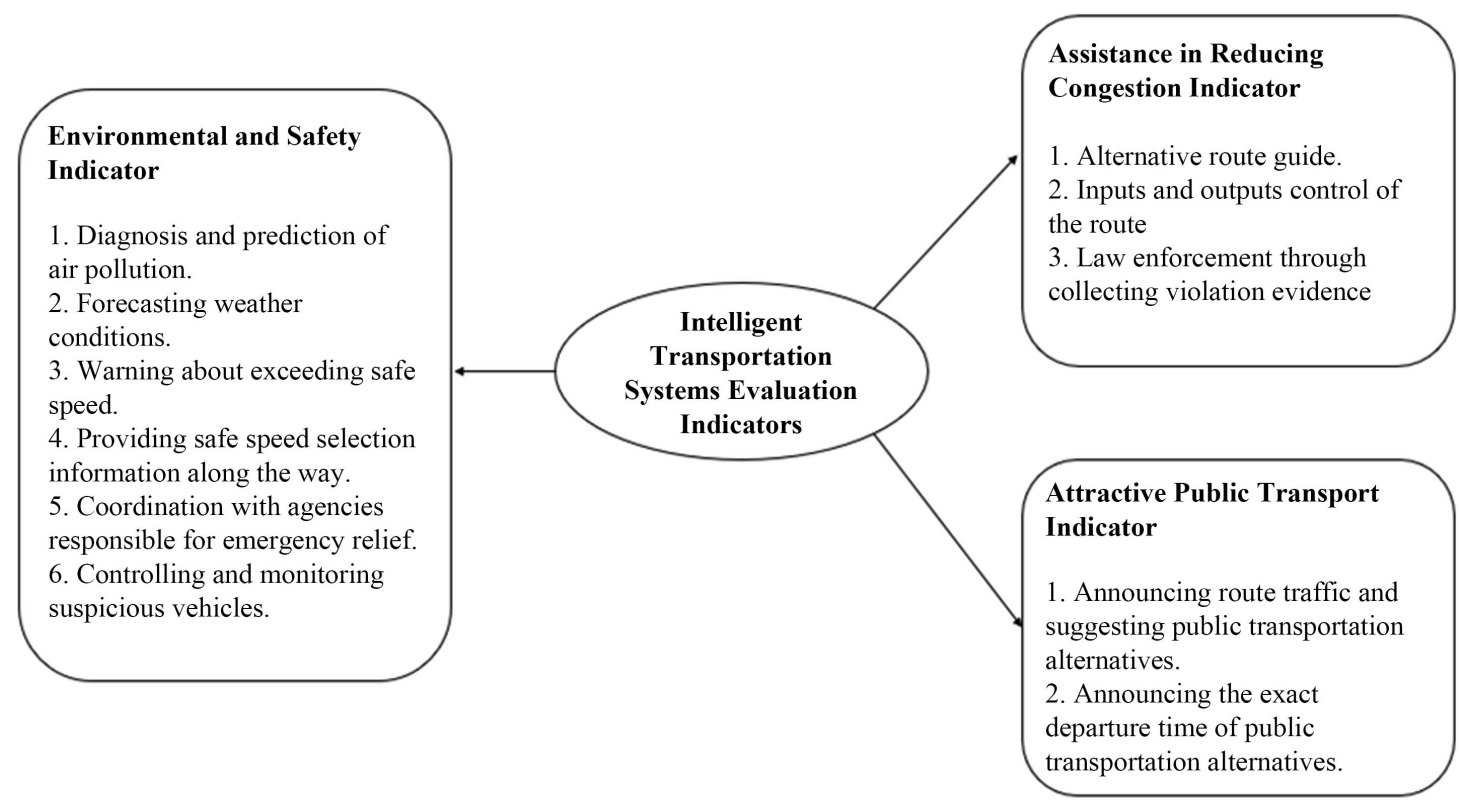

Figure 2. Final proposed indicators. 
routes in Iran (Tehran-Karaj Freeway). It is worth mentioning that this limitation cannot call into question the results of this paper since the majority of main transportation routes in Iran are not equipped with Intelligent Transportation Systems. Moreover, it is undoubtedly true that this research has an acceptable contribution to providing ITS evaluation indicators; therefore, the chosen indicators in this study could be the basis for evaluating ITS in future research.

\section{Conflicts of Interest}

The authors declare no conflicts of interest regarding the publication of this paper.

\section{References}

[1] Rother, M. (2009) Toyota Kata: Managing People for Improvement, Adaptiveness and Superior Results. McGraw-Hill Education, New York.

[2] Figueiredo, L., Jesus, I., Machado, J.A.T., Ferreira, J.R. and Martins de Carvalho, J.L. (2001) Towards the Development of Intelligent Transportation Systems. IEEE Intelligent Transportation Systems, Oakland, 25-29 August 2001, 1206-1211. https://doi.org/10.1109/ITSC.2001.948835

[3] Qi, L. (2008) Research on Intelligent Transportation System Technologies and Applications. Workshop on Power Electronics and Intelligent Transportation System, Guangzhou, 2-3 August 2008, 529-531. https://doi.org/10.1109/PEITS.2008.124

[4] Zhankaziev, S., Gavrilyuk, M., Morozov, D. and Zabudsky, A. (2018) Scientific and Methodological Approaches to the Development of a Feasibility Study for Intelligent Transportation Systems. Transportation Research Procedia, 36, 841-847. https://doi.org/10.1016/j.trpro.2018.12.068

[5] Qureshi, K.N. and Abdullah, A.H. (2013) A Survey on Intelligent Transportation Systems.

[6] Hwang, L.-C. (2013) M-GREEN: An Active Queue Management Mechanism for Multi-QoS Classes. Computer Standards \& Interfaces, 36, 122-131. https://doi.org/10.1016/j.csi.2013.07.007

[7] Annino, J.M. and Cromley, R. (2005) Intelligent Transportation Systems and Travel Behavior in Connecticut. The Professional Geographer, 57, 106-114.

[8] Samadi, S., Rad, A.P., Kazemi, F.M. and Jafarian, H. (2012) Performance Evaluation of Intelligent Adaptive Traffic Control Systems: A Case Study. Journal of Transportation Technologies, 2, 248-259. https://doi.org/10.4236/jtts.2012.23027

[9] He, J., Zeng, Z. and Li, Z. (2010) Benefit Evaluation Framework of Intelligent Transportation Systems. Journal of Transportation Systems Engineering and Information Technology, 10, 81-87. https://doi.org/10.1016/S1570-6672(09)60025-8

[10] Chen, K. and Miles, J.C. (1999) ITS Handbook 2000: Recommendations from the World Road Association (PIARC), PIARC Committee on Intelligent Transport. Artech House, London. https://trove.nla.gov.au/version/46595289

[11] Pan, H.-H., Wang, S.-C. and Yan, K.-Q. (2014) An Integrated Data Exchange Platform for Intelligent Transportation Systems. Computer Standards \& Interfaces, 36, 657-671. https://doi.org/10.1016/j.csi.2013.08.015

[12] Ghosh, S., Lee, T. and Lee, T.S. (2000) Intelligent Transportation Systems: New Principles and Architectures. CRC Press, Boca Raton.

https://doi.org/10.1201/9780203009949 
[13] Marell, A. and Westin, K. (1999) Intelligent Transportation System and Traffic Safety: Drivers Perception and Acceptance of Electronic Speed Checkers. Transportation Research Part C: Emerging Technologies, 7, 131-147. https://doi.org/10.1016/S0968-090X(99)00016-9

[14] Euler, G.W. (1990) Intelligent Vehicle/Highway Systems: Definitions and Applications. ITE Journal, 60, 17-22. https://trid.trb.org/view/348811

[15] Li, R., Kido, A. and Wang, S. (2015) Evaluation Index Development for Intelligent Transportation System in Smart Community Based on Big Data. Advances in $\mathrm{Me}$ chanical Engineering, 7, Article ID: 541651. https://doi.org/10.1155/2014/541651

[16] Hassan, M.H., Tizghadam, A. and Leon-Garcia, A. (2019) Spatio-Temporal Anomaly Detection in Intelligent Transportation Systems. Procedia Computer Science, 151, 852-857. https://doi.org/10.1016/j.procs.2019.04.117

[17] Yan, X., Zhang, H. and Wu, C. (2012) Research and Development of Intelligent Transportation Systems. 11 th International Symposium on Distributed Computing and Applications to Business, Engineering Science, Guilin, 19-22 October 2012, 321-327. https://doi.org/10.1109/DCABES.2012.107 